\title{
América Latina frente a los desafíos globales
}

\author{
Xavier Gorostiaga,s.j.
}

\section{Introducclón}

El conjunto de reuniones y seminarios realizados a nivel latinoamericano e internacional en 1990-91 pertila un diagnóstico común del carácler de la crisis, de las tendencias dominantes y sus conlratendencias en un conjunto de propuestas alternativas sorprendentemente coincidentes, en un momento dominado por la crisis de paradigmas, crisis de teoría y crisis de una visión allernativa de la sociedad y de la hisloria.

La profundidad y rapidez de los cambios globales hacen de los afios novenla una coyunlura estralégica: se está definiendo a corto plazo la correlación de fuerzas intemacionales que dominarán el comienzo del siglo XXI. El carácler estructural de eslos cambios y su globalidad tienen el sentido de una cuarta onda larga de los ciclos anunciados por Kondatrief. Por eso la coyuntura de la década del 90 es estratégica.

En otro sislema de coordenadas, lambién vivimos una encrucijada de cambios copemicanos, superiores a lo que signilicó el lapso de 1914-17. En aquellos anos el siglo $X X$ comenzó atrasado, con la gran controntación EsteOeste. El siglo XXI ya comenzó con la controntación Norte-Sur, capital-trabajo, que supone una nueva fase de la vieja controntación, pero con parámelros cualitativamente nuevos.

El ano de 1992, por olro lado, es un año simbólico. No se puede celebrar el descubrimiento de América, que ya lenía su propia identidad y civilización cuando llegaron los espanoles. Lo que ocurrió en 1492 fue 
el descubrimiento de la Historia Universal y el descubrimlento del mundo como tolalidad. En la década de los 90 , lambién, la humanidad se descubre como un mundo, una unidad inseparable, una casa común vinculada a un destino común de humanidad, producto de la revolución tecnológica, de la revolución inlormática, de las comunicaciones sociales, del transporte y de la crecienle conciencia del peligro de un suicidio colectivo por haber superado los límiles comunes colocados por la naluraleza.

Más allá de su simbolismo, 1992 es un tremendo desaflo para el autodescubrimienlo y la autoconstrucción de América Latina, superando el encubrimiento de estos $\mathbf{5 0 0}$ anos. Esle desalío se da, con todo, en el liempo del cólera, que refleja la profundidad de la crisis económica y política de América Latina. En estos tiempos del cólera estalla, lambién, el éxodo masivo de los Kurdos, el desastre ecológico de Bangladesh, la guerra civil en Yugoslavia y la desintegración de la Unión Soviélica. La persistente y crecienle hambre de Alrica supera en dramalicidad lodo el conjunto de las otras Iragedias humanas en el momento en que se proclama irresponsablemente el fin de la hisloria y el nuevo orden internacional.

Lo que se pretende subrayar desde la introducción es el carácter de globalidad, el carácter contradictorio y dialéclico de eslos cambios estructurales. Entre la esperanza y el desgaste, la impotencia y el cólera, la angustia y la rabia, se debale la intelectualidad latinoamericana, mientras el pueblo se vuelve para sobrevivir en medio de una creciente miseria.

Intentaremos desentrañar esla encrucijada de los 90 analizando en la primera parte las causas esiructurales de la misma, en el marco más amplio de la reestructuración del capilalismo y del Nuevo Orden Mundial que se proclamó después de la Guerra del Golfo. En una segunda parte sopesaremos el impacto de eslos cambios en América Latina y el Caribe, la propuesta de la Iniciativa para las Américas frente a la conformación de los megamercados trilaterales y la recesión norteamericana. Finalmente, indicaremos algunos rasgos de la dialéclica entre la democracia creciente y el sometimiento económico, ambos fenómenos causantes de una crisis de ingobemabilidad y desgaste político que atecta tanto a la izquierda como a la derecha latinoamericana. La crisis de civilización frente a esta avalancha neoliberal. La úllima encíclica papal Centesimus Annus, en el centenario de la Rerum Novaru, refleja hasta dónde esla avalancha del Norte contra el Sur y del Capital contra el Trabajo ha superado limites que hasta muy recientemente habian sido considerados como un mal menor. 


\section{Los camblos}

Coincidimos con el historiador Paul Kennedy en que no ha existido en la historia de la humanidad un periodo en el que se dé tanta concentración, centralización e imtensidad del capital en tan pocas naciones y en una población tan minorilaria. El grupo de los Siete y el capilalismo central con unos $\mathbf{8 0 0}$ millones de habilantes, controlan y hegerinonizan más poder económico, tecnob́gico, informálico y militar que el resto de los aproximadamente cuatro mil millones de personas que viven en Asia, Africa, Europa Oriental y América Latina, donde también una exclusiva minoria participa de las relaciones y eslándar de vida del Norte. Esta concentración del lcapital corresponde al carácter de la nueva revolución tecnológica, donde el ciclo de acumulación del capital dependel cada vez menos de la inlensidad de los recursos nalurales y del trabajo. e incluso de la intensidad del capital productivo, para concentrarse en una acumulación tecnológica basada en la intensidad del conocimiento. La concentración y centralización del conocimienlo lecnológico es más intensa y monopolica que las otras formas de capilal, aumentando la brecha entre el Norte y el Sur.

La repercusión de esle fenómeno ha llevado a una desmaterialización crecienle de la producción, donde cada vez se requieren menos materias primas por unidad de produclos. (En el cuadro 1 se puede comprobar cómo en la producción japonesa se ha dado la reducción de un $33 \%$ del uso de malerias primas en relación con el producto en los últimos 20 anos).

Más significativo todavía es el ritmo acelerado de la desmaterialización, el cual se incrementó casi 6 veces, pasando de $-0.6 \%$ anual entre 1965-76 a una reducción del uso de Materia Prima-Producto Industrial superior al $3 \%$ desde 1980 .

El efecto de la desmaterialización se manifiesta en la tendencia a la caida de los precios reales de las 33 principales materias primas, la mayoría de ellas producto de exportación del Tercer Mundo. Este deterioro es más pronunciado también en los últimos afios.

Por otro lado, la automatización y robolización de la producción provoca que el trabajo pierda su valor relalivo trente al capital, tanto en el Norte como en el Sur. Ambos procesos provocan un delerioro permanente y estructural del valor relalivo de las supuestamente consideradas venlajas comparativas del Sur en la producción y comercio mundial.

Eslos fenómenos coinciden con una transnacionalización y globalización del sistema de producción, linanciamiento y comercialización, que permite por primera vez la posibilidad de un mercado global. 


\section{Cuadro 1}

Japón: Industria manufacturera: relación consumo materias

primas/producción industrial (1965-1987).

(Indices de producción industrial y de consumo de materias primas: $1980=100$ ).

\begin{tabular}{|c|c|c|c|}
\hline Ano & $\begin{array}{l}\text { Producción } \\
\text { Industrial }\end{array}$ & $\begin{array}{c}\text { Malerias } \\
\text { Primas }\end{array}$ & $M P / P \mid$ \\
\hline 1965 & 32.5 & 3.5 & 1.154 \\
\hline 1966 & 36.8 & 42.8 & 1.163 \\
\hline 1967 & 43.9 & 51.8 & 1.180 \\
\hline 1968 & 50.2 & 57.9 & 1.153 \\
\hline 1969 & 58.4 & 67.6 & 1.158 \\
\hline 1970 & 66.5 & 76.2 & 1.146 \\
\hline 1971 & 68.3 & 76.2 & 1.116 \\
\hline 1972 & 73.3 & 81.7 & 1.115 \\
\hline 1973 & 84.4 & 95.2 & 1.128 \\
\hline 1974 & 81.1 & 90.4 & 1.115 \\
\hline 1975 & 72.1 & 80.2 & 1.112 \\
\hline 1976 & 80.2 & 87.5 & 1.091 \\
\hline 1977 & 83.5 & 89.8 & 1.075 \\
\hline 1978 & 88.9 & 93.3 & 1.049 \\
\hline 1979 & 95.5 & 99.9 & 1.046 \\
\hline 1980 & 100.0 & 100.0 & 1.000 \\
\hline 1981 & 101.0 & 94.8 & 0.939 \\
\hline 1982 & 101.4 & 91.4 & 0.901 \\
\hline 1983 & 104.9 & 92.2 & 0.879 \\
\hline 1984 & 116.7 & 99.6 & 0.853 \\
\hline 1985 & 122.0 & 101.3 & 0.830 \\
\hline 1986 & 121.6 & 97.5 & 0.802 \\
\hline 1987 & 126.7 & 98.5 & 0.777 \\
\hline
\end{tabular}

Fuente: Banco de Japón, Economic Statiscal Annual, 1985, "Key Statics". Oficina de Estadistica del Japón, Monthly of Japan, No. 317, "Key Slatistics", noviembre de 1987.

Un sistema de mercado del que no se puede prescindir ni marginarse, incluso aquellos países con más capacidad de autarquía.

La revolución biotecnológica refuerza esa relativa autonomia del conocimiento frenle a condiciones climatológicas, genélicas y naturales, transformando las ventajas comparativas de la teoría clásica en forma 
definitiva.

Las nuevas áreas de expansión de los procesos de acumulación global para fin de siglo, como son el espacio, el mar y la energla quedan totalmente supeditadas al control del poder económico, tecnológico y militar, lo que provocará una mayor concentración y centralización y, por lo tanlo, una mayor brecha y asimetrla entre el Norte y el Sur.

La revolución en las telecomunicaciones, transporte e inlormática ha producido innovaciones en la gestión que ha facilitado aún más las lusiones de capital y tecnologla donde las empresas privadas de América Latina y del Sur han sido cada vez más incorporadas e insertadas en forma dependiente a la lógica del capital cenlral. La empresa nacional, tanto privada como estatal, cada vez queda más marginada y en posición asimétrica trente a la empresa transnacional, crecientemente aislada de la lógica del mercado interno y de la lógica de sobrevivencia de las grandes mayorlas pauperizadas.

Los paises subdesarrollados, con un $75 \%$ de la población mundial, apenas alcanzan el $19 \%$ del PBI mundial, habiendo reducido su participación del $23 \%$ que alcanzaban hace una década. Su participación en la inversión extranjera bajó de un $25.2 \%$ a un $16.9 \%$, lo que de nuevo refleja la globalidad del fenómeno. El cual es aún más grave si consideramos que en esa misma década las transferencias netas del Sur al Norle fueron el equivalente a 10 Planes Marshall. En el caso de América Latina, y según el más recienle informe del SELA, el mero servicio de la deuda fue un $80 \%$ superior a los monlos de la inversión extranjera. Si se incluyera el capital lalinoamericano en el Norte, del orden de 160 mil millones y el deterioro de los términos de intercambio, de unos $100 \mathrm{mil}$ millones, la debacle financiera y productiva de América Latina en la década de los $\mathbf{8 0}$ podría equipararse a los peores anos de saqueo colonial.

A esle fenómeno estructural to hemos calificado como la avalancha del Norte contra el Sur y del capital contra el trabajo. No ha exislido en la historia, ni siquiera en la época colonial, una bipolarización tan extrema del mundo. Este es el carácter fundamenlal de los cambios estructurales del fin de siglo, al menos desde la percepción de los pueblos de América Lalina y del sur. La llamada africanización de América Latina es una realidad objeliva. En la Década de los 80 América Latina disminuyó su participación en el mercado internacional de $7 \%$ a $4 \%$; el stock de inversión exIranjera directa de $12.3 \%$ en 1980 a $5.8 \%$ en 1989 , siendo la región del mundo con mayor retroceso incluso mayor que Africa, que descendió de $2.4 \%$ a $1.9 \%$. 
No debe por tanto sorprender que la CEPAL reconozca que, en la misma década, el número de población a nivel de pobreza en América Latina haya ascendido de 112 a 184 millones de personas.

\section{Camblos politicos globales}

En los últimos anos, cuatro hechos fundamentales están marcando las características polílicas de los 90: el colapso del socialismo estatista y lolalitario, la nueva unidad europea, la pérdida creciente de la hegemonía económica norteamericana y el nuevo papel de Japón y el Paclflco.

La profunda crisis de Europa del Este ha tenido dramáticas repercusiones globales, iniciando una nueva lase histórica con el fin de la Guerra Fría. Desde el Tercer Mundo, la evaluación de eslos cambios es muy compleja. En primer lugar, la pregunta desde la experiencia latinoamericana es si realmente hubo socialismo en Europa del Este. Es decir, socialismo extendido como sistema altemativo social, economica y polltico al sistema capitalista. El debate latinoamericano se inclina más bien a pensar que un socialismo alternativo en la Unión Soviética posiblemente no superó el período de los soviels 1923-1924. Posteriormente, la Unión Soviética se volvió una alternaliva militar frente a la amenaza nazi y después de la derrola de los nazis, una alternativa militar frente a la amenaza de la guerra termonuclear. La mayorla de los países de Europa del Esle nunca luvieron un socialismo original, sino una alianza militar defensiva e impuesta en torno a la Unión Soviética. El impacto negativo de este estilo de socialismo, militar y estatista fue grande en América Latina. El dogmatismo, verticalismo y estatismo de la experiencia del Este europeo alectó a todos los partidos comunistas y a la mayoría de la izquierda latinoamericana. Por otro lado, sin embargo, el bloque socialisla sirvió como un balance que permitía un espacio geopolílico y una relaguardia de apoyo para los cambios en el Sur.

El colapso de Europa del Este supone una pérdida de paradigma, de balance económico y geopolítico, pero a la vez un nuevo espacio ideológico y práctico para abrir nuevas experiencias, tanto políticas como económicas en un mundo que tiende a buscar la superación de los confliclos a través de la negociación, el derecho inlernacional, nuevas normas de convivencias que profundicen la democracia en las relaciones globales tanto económicas como políticas.

El socialismo real o socialismo de Estado que tuvo éxito en la liquidación del poder leudal y en la creación de una base industrial importante colapsó rotundamente anle la revolución lecnológica y la sociedad de consumo. La crisis de democracia es, sin embargo, la raiz política del 
colapso de esta experiencia de sociedad Estado.

El espejismo de Occidente puede opacarse prontamente en algunos países del Esle, como en la anligua Alemania y en Polonia, anle la vorágine de un mercado que no respeta hábitos, ni se preocupa por consecuencias sociales, ni por la cullura y la identidad nacional. La mayor parte de Europa del Este camina hacia una latinoamericanización veloz, pudiendo convertirse en un área de recursos nalurales y de mano de obra barala para el desarrollo de Europa y del Norte. La ex URSS enfrenta posiblemente mayores relos ante la amenaza de la desintegración de la lederación y también de un golpe militar o formas de fascismo populista.

En los próximos años, Europa del Este absorvará la atención política y la mayor parte de los recursos disponibles en Europa, afectando política y económicamente la atención que el Sur requiere. El impacto de los cambios en Europa del Este, sin embargo, puede ser distinto para el Sur a mediano y largo plazo que lo que lo ha sido en el corlo plazo de esta breve experiencia. La relación directa entre el Sur y el Este, transformados por la crisis de sus sociedades civiles, puede convertirse a mediano plazo en una de las fuentes de creatividad y complemenlariedad mundial. Para ello habrá que superar la compleja siluación y el actual aislamiento de ambas sociedades civiles.

La unidad europea hegemonizada por la unificación alemana ha cambiado la correlación de fuerzas internacionales. De Yalta a Malta, de febrero de 1945 a diciembre de 1989, en menos de medio siglo, el mundo ha sufrido Iransformaciones que históricamente hubiesen requerido varias centurias, tanto en lo ideológico, como en lo político, en lo económico y por primera vez, desgraciadamente, en lo ecológico. Una Europa unida podrá convertirse en el eje productivo, financiero y comercial del mundo, junto con Japón y el Pacílico, dejando en una situación cada vez más disminuida a Estados Unidos, provocando un nuevo reparto de las esieras de influencia. Se abre, por lanto, la posibilidad para los países del Sur de aprovechar los nuevos espacios y contradicciones del sistema.

La pérdida de hegemonia económica norteamericana es un fenómeno coincidente con el debilitamiento y colapso del sistema de Europa del Este, la unidad europa y la emergencia de Japón y el Pacífico. La pérdida de hegemonia de Eslados Unidos liene evidentemente raíces económicas, por su incapacidad de superar los déficil fiscales y comerciales, por su gigantesco presupuesto militar, al basar el crecimiento de la úllima década en un endeudamienlo vertiginoso que ha transformado al único pais que tenia el privilegio de tener una moneda nacional como 
reserva internacional, en el pais más endeudado del globo. En estas condiciones resulta dificil evitar una recesión sin un flujo masivo anual neto de más de 100 mil millones de dólares.

La pérdida de compelitividad tecnológica y de productividad no permiten mantener una hegemonia política si no es basándola lundamentakmente en un poder militar, 10 que exige un presupuesto de defensa de aproximadamente 300 mil millones de dólares anuales, $y$ en el poder ideológico con el que controlar las dos terceras partes de lodas las imágenes producidas en el mundo. La inestabilidad financiera manifestada en oclubre de 1988 y más recientemente en la crisis financiera de las instiluciones de ahorro y crédito, y en el deterioro creciente de la infraesinctura productiva y social del pais, indican que la deuda, los déficil y el presupuesto militar no son sostenibles por más tiempo en eslas condiciones. La crisis del Golio podría allerar lemporalmente la recesión norteamericana y el balance político mundial, pero sin cambiar las tendencias estruclurales aqui sefnaladas.

Japón y el sudesle asiálico en esta Era del Pacífico, emergen como un poder industrial, financiero y tecnológico determinante al linal del siglo. Sin embargo, Japón, gigante económico, se presenta como un pigmeo polílico. La diplomacia de Japón no ha sido capaz todavía de jugar un papel correspondienle a su poder económico. La política exterior de Japón sigue siendo un misterio oriental para América Latina.

Desde América Latina y desde el Sur se percibe a Japón, su hisloria, su cultura, su raza y su religión en forma dilerente a como lo percibe el Norle. Los japoneses no son blancos no son occidentales ni son cristianos. Pero las fuerzas estructurales del mercado y de las instituciones del Grupo de los Siete tienden a asimilar a Japón con el Norle, aumentando de esla forma la avalancha del Norle contra el Sur y del capital contra el trabajo.

Estos tres grandes bloques conforman un neolrilateralismo hegemonizado por el grupo de los Siete, con un conjunto de instituciones mundiales organizadas bajo su hegemonia y el conlrol (FMI y Banco Mundial). La propia Organización de las Naciones Unidas, con su dependencia financiera y el poder de veto de las potencias en el Consejo de Seguridad, mantiene un esquema originado en la Guerra Fría, donde la mayoría de los paises no pueden beneficiarse de una participación equitaliva y democrálica.

La amenaza que confrontan los palses del Sur se ve alimentada por la alianza de intereses geo-económicos de los paises del Grupo de los Siele, incapaces de atender y enlender las particularidades culturales, religiosas y nacionales de los múltiples pueblos del Sur, que se sumer- 
gen en un lenómeno de creciente pobreza y marginación. La propuesta que se ofrece, desde el norle, es la inlegración a esta cullura de mercado con una liberación del comercio, de las finanzas, con la privalización de la economía reduciendo el espacio de autonomia de los Eslados, asumiendo que las fuerzas del mercado son capaces de superar la pobreza y lograr la estabilidad política y democrática de un mundo cada vez más unificado.

El multipolarismo de la realidad de tin de siglo es ambiguo. Aunque ofrece nuevos espacios y posibilidades de diversificación si se utilizan los márgenes de maniobra que los intereses diferentes y conlradiclorios entre los tres grandes bloques permiten, sólo una vinculación interdependiente de los intereses del Sur pudiera crear una capacidad de negociación y acción significaliva como para incidir con eficacia en esta década.

\section{América Latina en esie fin de siglo}

Hace 500 afios el mundo se descubrió - se conoció- como una unidad geográlica histórica. El mundo se descubre y conoce en 1992 como una entidad inseparable, aunque dramáticamente dividida. El Norte trilaleral, articulado en torno al Grupo de los Siete, aumenta la concentración y centralización del poder en todas sus formas. La reestructuración del sistema capilalista tiende actualmente a reforzar esa polarización y asimetría al faltarle el contrapeso que ofrecia el bloque de los países socialislas del Este. Nunca antes en la hisloria, ni en los tiempos de la Colonia, ni en las guerras mundiales, ni en la bipolarización de la Guerra Fria entre el Este y el Oeste, la división del mundo entre los que tienen el poder (militar, tecnológico, financiero, informático, administrativo) y los que carecen y dependen de ese poder ha sido tan asimétrica.

La división del mundo, unido sin embargo por primera vez, entre el Norte de los pocos con mucho y el Sur de los muchos con poco, se transforma en el eje y carácter de la actual crisis del fin de siglo. Ciertamente, la caliticación Norle y Sur simplifica el problema mundial, pero permite resaltar la contradicción dominante en momentos en que hablar de Tercer Mundo ha perdido sentido con la desaparición del Segundo Mundo.

En estas condiciones, el modelo de sociedad al que lleva el eslilo de civilización de los paises del Norte es un modelo de sociedad no universatilizable. El eslilo de desarrollo y el modelo de vida de los paises del Norte no es extensible a loda la humanidad, por tener límiles ecológicos, poblacionales y por ser estrucluralmente contradictorio. Contradictorio 
entre los requerimientos de la acumulación crecienle del capital, la tecnología y el poder en el Norte, y la exclusión de las mayorias del Sur, que exigen no sólo la sobrevivencia sino la participación y un nivel de vida humana que permita la democracia y la paz.

Es revelador que precisamente cuando se anuncia ol fin de la historia $y$ el triunio del sistema capitalista occidental, el Banco Mundial publique el informe sobre el Desarrollo Mundial 1990: La Pobreza, planteando ésta como "la cuestión más apremiante de la década". El fenómeno de los mil millones de personas con un percápila menor de $\mathbf{3 7 0}$ dólares al ano no es solamente vergonzoso, es insostenible.

Esta crisis no es sólo de distribución y equidad, es una crisis de valores y de destino para la humanidad. Por eso puede calificarse como una crisis de civilización. La sociedad mundial no es ni estable ni sostenible en estas condiciones. La democracia y sus demandas son irrealizables para la mayoria de la población del mundo, lo que tiende a provocar una ingobernabilidad creciente. Huntinglon, el ideólogo de la Comisión Trilateral en la década de los 70 , calificó como una amenaza el incremento de las demandas producidas por la democratización en el Tercer Mundo. La urgencia de reducir y de tutelar la democracia de las grandes mayorias en el Sur se vuelve hoy una necesidad imperiosa si el Norte quiere mantener los privilegios que disiruta. Lo que hemos calificado como "democracia de baja intensidad" para América Lalina es un producto más estructural que conyuntural, proveniente de la incapacidad de nuestra base material de sostener incluso estos incipientes procesos de democratización.

Para legitimar esta situación se percibe un inlenlo de ideologización de la confrontación, Norte Sur, presentando al Sur como el nuevo enemigo, como la amenaza que sustiluye al desaparecido imperio del mal. El Sur se presenta como el tugurio del mal, un lugar peligroso para la eslabilidad ciudadana del Norte de donde provienen las amenazas de la droga, la invasión de la migración, la inestabilidad polílica y los conllicios regionales.

La objeliva brecha esIructural enlre el Norte y el Sur se amplifica con la ideologización subjeliva, que tiene prolundos rasgos racistas. En vez de entrentar las causas de la crisis se busca en sus electos la responsabilidad de la misma.

\section{América Latina: la cosecha de los 80}

La llamada década perdida es una década compleja y dialéctica. Indudablemente que la capacidad competitiva de América Lalina en los 90 
es sustancialmente menor que en los 80 . Las pérdidas en el comercio exterior, es la participación de la inversión extranjera, en la protunda descapitalización y desinversión tanto productiva como social, y los demás Indices suficientemente conocidos de la década perdida, indican un prolundo y esiructural deterioro económico de América Latina. Robert Mac Namara sintelizo esta percepción con una afirmación rolunda: Latin America no business. No somos negocio. Posiblemente, sólo México, Chile, y en cierta forma Brasil, Colombia y Venezuela, ofrecen un panorama más atractivo para el capital. La aparición del collera en los tiempos del ajuste simboliza esta creciente atricanización y marginación económica de América Latina.

Por otro lado, la marginación política es también evidente ante la conflictividad del Medio Oriente y de los intereses estralégicos allí involucrados, y ante la creciente desintegración de la Unión Soviélica, por la tensión en las diferentes nacionalidades. El propio Gorvachov mencionó la amenaza de la desintegración en su viaje a Japón en abril y la amenaza del retorno de la Guerra Fría a mediados de mayo. La década perdida sin embargo es mucho más compleja. La sociedad latinoamericana es cualitativamente diferente de lo que fue al inicio de los 80 . La década perdida coincide y es en parte causa de la explosión de la democracia latinoamericana en los 80 . La democratización a través de los procesos electorales no es más que un reflejo de una democracia radical y profunda que se ha ido consolidando en forma creciente sobre los diversos ámbitos de la sociedad civil. Décadas de lucha contra la oligarquias, las dicladuras y el militarismo han ido cuajando en una revolución de la sociedad civil. Como manifestaron en abril de 1991 los represenlantes de los partidos políticos latinoamericanos en Viena: "La incipiente democracia electoral en muchos paises se manifiesta en la democracia representativa, que tiende a convertirse, por la presión democrática y conslitucional de las mayorias, en una auténtica democracia participativa".

Este despertar de la sociedad civil lalinoamericana en los tiempos de cólera responde a un proceso continuo que logra ir superando las limitaciones y la falla de credibilidad en las elecciones, que se manifiesta on un alto abstencionismo en los procesos electorales.

Esıa compleja dialéctica de la crisis económica de la década perdida y la revolución de la sociedad civil aparece como el carácter de la década de los 80 . La participación democrática de las mayorlas organizadas y movilizadas en sus propias inslituciones civiles, han creado nuevos sujelos históricos que proponen y demandan su participación en la economia, política, cultura y religión. 
Esta dinámica de la sociedad civil, tiene obviamente notables excepciones, como Guatemala, Argentina, Panamá y Peni. La cultura del terror impuesta por la represión militar en los dos primeros casos, la ocupación militar norteamericana de Panamá y el colapso económico en el pais andino explica la disgregación de la sociedad civil en estas naciones. Esta dinámica contradictoria provoca un fenómeno de ingobemabilidad, donde las demandas que nacen como producto del avance de la democracia no encuentran una base material de suslento. Esta ingobernabilidad se manifiesta en el rápido desgaste del liderazgo polítlco neoliberal que controla la mayoria de las democracias electorales desde la segunda milad de los 80 . Los casos de Ménem, Collo de Mello, Fujimori, Cristiani y Callejas no son más que ejemplos de un fenómeno que se manifiesta en loda su patélicá crudeza en la ingobernabilidad de Panamá y Nicaragua. En ambos paises el proyecto pronorleamericano y neoliberal no consiguió estabilizar políticamente al país ni reactivar la economía, provocando un claro desgaste politico e incluso profundas divisiones en ambos gobiernos, y una aparentemente sorpresiva incapacidad linanciera de Estados Unidos para apoyar dos gobiemos que podrían haberse convertido en un show case, en una vilrina o aparador para mostrar las maravillas de la política norteamericana.

La ingobernabilidad está provocando por una parte, una sociedad de mendigos y delincuentes, de descamisados y de lumpen que buscan la sobrevivencia individual a cualquier costo. Esta masa desorganizada es uno de los nuevos lemas que desafían los proyectos alternativos en América Latina. Una masa fácilmente caplable por religiones escapistas, por la droga, por la migración creciente hacia el exterior o por un ultra izquierdismo violenlo desconectado de propuestas allernativas y viables, que incluso confrontan a los grupos organizados y a los partidos con propuestas alternativas de sociedad. En esta encrucijada de fin de siglo se presentan dos proyeclos contradictorios para el continente, que son más bien dos procesos y dos visiones antagónicas sobre el fuluro de América Lalina.

\section{Deuda, ajuste neollberal e InIclativa}

La conlinuidad de la crisis de la deuda, el proceso de ajustes estructurales y la nueva propuesta de Bush para el continente permiten visualizar un proyecto de reestructuración del capitalismo latinoamericano para la nueva insersión internacional del continente, en el que se establece el papel que América Latina debe tener en el Nuevo Orden Mundial de Bush y Baker proclamaron en el "momento definitorio de la Guerra del Golfo". 
En aquella ocasion, el presidente Bush atirmo ante el Congreso: "No hay sustilutos para el liderazgo americano en el mundl" $Y$ el Secrelario de Estado declaró ante el Comité de Relaciones Exteriores del Congreso: "Quedamos nosotros. Permanecemos como la única Nación que tiene voluntad polílica. Los instrumentos militares y economicos a nuestra disposición para conlrolar la ilegalidad que está dominando en ciertas áreas del mundo. El mundo se ha convertido en un lugar peligroso y nosotros necesitamos capacidad global. Somos la única super potencia que permanece".

La deuda ha sido el inslrumento financiero que sustituyó a la inversión directa en la década de los 70 como mecanismos de exiracción de transferencias nelas de América Latina. A la vez, mecanismos de sometimiento del Estado, y de la desnacionalización, incluso la empresa privada latinoamericana. Los conatos de América Latina, por enfrentarse individualmente al pago de la deuda no consiguieron, a pesar de los diversos intentos de declaración de moraloria, lograr una negociación equilativa de la deuda. El Fondo Monetario, el Banco Mundial, la AID y, más recientemenle el BID, sirviéndose de las obligaciones de la deuda consiguieron crear condicionalidades cruzadas sobre los Eslados y las empresas nacionales, de forma que las políticas de ajuste vinculadas a estas condicionalidades sobreimpuestas han provocado un grave debilitamiento en la capacidad negociadora de América Lalina. En este proceso debe entenderse la iniciativa para las Américas que el presidente Bush anunció en julio de 1990.

La propia Secretaria Ejeculiva del SELA, en su reciente y positivamente ponderado análisis sobre la iniciativa de Bush (abril 91) alirma: "La iniciativa para las Américas no propone una eslrategia para el desarrollo de la región, sino que conslituye un mecanismo para acelerar las reformas económicas en curso, cuyos elemenlos principales han sido promovidos desde los organismos financieros mullilaterales, con el apoyo del gobierno norleamericano...Responde a necesidades económicas y estratégicas concretas de los Estados Unidos". EI SELA propone por esto la búsqueda de elementos que permitan alcanzar beneficios mutuos dentro de una identiticación de los intereses muluos que logren una auténtica asociación, lo cual exige definir las reglas del juego y crilerios de entendimiento, con Eslados Unidos.

Mantenemos la tesis de que la iniciativa Bush es producto de la necesidad del reajusle macroeconómico de la economía norteamericana debido a su honda recesión y a su falla de competitividad internacional. Estados Unidos necesita la creación de un mercado continental para enfrentarse a Europa unida y a su nueva zona de influencia económico 
política en Europa del Este y al megamercado de Japón y del sudesle asiático.

La ampliación de un mercado libre desde Alaska a la Patagonia permitiría a Estados Unidos compartir los costos de su propio ajuste con Canadá y América Latina, al mismo tiempo que aumentar el poder de negociación frente a los acuerdos comerciales globales que se debaten en la Ronda Unuguaya. Ante el posible Iracaso de estos acuerdos comerciales, Estados Unidos necesila ampliar su capacidad competitiva para enfrentarse a acuerdos comerciales, bilaterales y multilaterales con Europa y el Japón.

La deuda, el comnercio y la inversión, los Ires pilares en la Iniciativa para las Américas llevan consigo estrictos criterios de condicionalidad que el presidente Bush ha enfatizado insistentemente. El documenlo ya mencionado del SELA alirma: "En todos los asuntos relativos a la deuda, la condicionalidad derivada de la vinculación con la reforma económica constituye un requisito esencial". Pensamos que este criterio se aplicará también a los asuntos comerciales y a la inversión. Eslo ya es evidente en relación con los mecanismos de mercado que no han sido aplicados para la reducción de la deuda, al no aceplarse las cotizaciones en el mercado secundario. En la misma lógica, las condiciones para la incorporación de la inversión norteamericana en América Latina estarán vinculadas a la aceplación de las condicionalidades de la deuda y del uso no recíproco y asimétrico del mercado, que nunca se extendlerá al flujo libre de la mano de obra entre Estados Unidos y América Latina, ni siquiera en el caso de México.

Partimos del presupueslo de que la inicialiva debe analizarse en primer lugar, desde la recesión y necesidad de un ajuste macroeconómica en Estados Unidos. La inicialiva permitiría a Estados Unidos enirentarse en mejores condiciones a su endeudamiento estruclural, a su pérdida de competitividad internacional, a la expansión de su mercado hacia una zona de influencia privilegiada para acrecentar su seguridad estralégica y el auloabastecimiento continental de recursos naturales, especialmente petróleo, para poder mantener su hegemonia geoestratégica en base a una competitividad geoeconómica de la que aclualmenle carece.

La deuda tolal de Estados Unidos, que se presenta en el siguienle cuadro, relleja que la economia norleamericana es en buena medida una economia ficlicia, dependiendo de transferencias inlemacionales superiores a los 100 mil millones de dólares y a un endeudamiento progresivo, tanto del estado como de las empresas y de los consumidores. 


\section{Cuadro 2}

Deuda de Eslados Unidos (miles de millones de dól.)

\begin{tabular}{crr}
\hline & 1980 & 1990 \\
\hline Deuda federal & 914 & 3,200 \\
Estatal & 316 & 850 \\
Empresas & 829 & 2,100 \\
Consumidores & 1,300 & 3,000 \\
\hline Total & 3,400 & 9,150 \\
\hline PBI & 2,732 & 5,300 \\
Deuda externa & +180 & -800 \\
Servicio/Presup. & $13 \%$ & $20 \%$ \\
Ahorro & $7 \%$ & $4 \%$ \\
\hline
\end{tabular}

Fuente: Recopilación de Anuarios de Comercio Exterior de EE.UU. 1987-90.

En una sóla década, Eslados Unidos pasó de ser el mayor acreedor inlernacional a ser el mayor deudor internacional duplicando casi el presupuesto que requiere el servicio de esta deuda (del 13 al $20 \%$ ) y reduciendo casi en la milad el ahorro del pais (del 7 al $4 \%$ ). Esta situación es absolutamenle inestable. Estados Unidos no puede seguir consumiendo el $25 \%$ de la energía del mundo, el $50 \%$ del cual es importado. No puede seguir manleniendo unos impuestos sobre la gasolina que son 6 veces inferiores a los de Japón, Alemania, Italia, Francia, etcétera. Si Eslados Unidos aumentara el impuesto de la gasolina al nivel de sus competidores económicos podría obtener un ingreso adicional de 180 mil millones de dólares anuales. Esle derroche de energía explica la firme decision de embarcarse en una operación militar en el Golfo.

A pesar de ese subsidio energético, la productividad norleamericana, medida en lérminos de PBI per cáplla, era en 1988 la cuarta entre la de las 22 naciones más industrializadas. La tendencia es que llegue a ocupar el lugar 13 en el afio 2030. La razón lundamental del declive de la productividad norteamericana es que su tasa de ahorro es la mitad de la de sus competidores industriales y una cuarta parte de la del Japón. Esta reducción del ahorro norleamericano contradice además una promesa fundamental de la política neoliberal, que mantiene que la concenIración del ingreso permite el aumento del ahorro y la inversión. En Eslados Unidos, la concentración del ingreso en el 10\% de los más ricos 
aumenló un $4 \%$ desde 1980 a 1990 , subiendo su proporción al $27 \%$ del PBI. En esa misma década, sin embargo, el ahorro decreció de 7 a $4 \%$. Por otro lado, el sistema impositivo norteamericano no ayuda a corregir esa deliciencia, pues el peso Iributario es un $55 \%$ del promedio del de los olros paises industriales.

Por otro lado, el gasto militar en Eslados Unidos, en relación con estos paises industriales, es 4 veces superior como porcentaje del PBI, al mismo tiempo que su gasto en aclividades no militares, como infraestruclura e inversión social, es $\mathbf{4 5 \%}$ más bajo que el de los olros paises induslriales. Estos datos están lomados de un les a la responsabilidad ciudadana de Eslados Unidos hecho por el Profesor William M. Kaula, de la Universidad de California y publicado por The New York Time y Herald Tribune el 12 de marzo de 1991.

La pérdida de competitividad internacional de Estados Unidos es también notable. En el cuadro 3 se percibe el declive en la misma década de casi un $50 \%$ en las áreas punta de la lecnología norteamericana, en libras óplicas, conduclores y maquinaria agrícola; al tiempo que su dependencia petrolera se triplica en esa misma década. En 1990 Eslados Unidos mantienen un liderazgo lecnológico en reducidas áreas, en especial la biolecnologia y el disefio industrial.

\section{Cuadro 3}

Competitividad en el mercado internacional

\begin{tabular}{l|cc}
\hline & 1980 & 1990 \\
\hline Fibra 6́ptica & 73 & 42 \\
Conductores & 60 & 36 \\
Maquinaria agricola & 18 & 7 \\
Dependencia petrolera & 12 & 36 \\
\hline
\end{tabular}

Fuente: Newsweek, Abril 1991.

Esta pérdida de compelitividad corresponde a una reducción en la lasa de inversión en los fondos dedicados a la investigación en la produclividad, en los gastos en inlraestructura e incluso en la pérdida de su propio mercado inlerno, que mantiene una propensión crecienle a aumentar las importaciones. El consumidor norleamericano comienza a desconfiar de sus productos, en relación con la tecnologia y el disefio de productos japoneses y europeos. La falla de confianza del consumidor esladounidense ha llegado a su punlo más bajo desde 1980, con una 
lasa de confianza del $54 \%$ en relación a la que lenla hace una década. Esta lalta de confianza ha comenzado a tener repercusiones internacionales. Japón ha relirado en 1990 más de 30 mil millones de dólares del mercado norteamericano. Por otro lado, la recesión prolongada ha provocado un aumento del número de los pobres, que supera los $\mathbf{3 0}$ millones de norteamericanos.

El mantener un alto presupuesto militar y el que dos terceras partes de los fondos dedicados a la investigación se dediquen a la alta tecnología militar, aumenta la brecha de competitividad $\infty$ n la lecnologla civil, sobre todo con la de Japón y la de Alemania, que no tienen tantos gastos en tecnología militar.

Este análisis pudiera extenderse con otros datos que indican la irrenunciable necesidad de un ajuste estructural de la economía de Estados Unidos. El tema ha llevado a grandes debales en el Congreso, e incluso a que el Presidente Bush luviese que romper con su principal promesa elecloral de no aumentar los impueslos. Eslados Unidos necesita un ajuste incluso más eslriclo que el requerido en América Latina. Además, las distorsiones de la economía norteamericana tienen un impacto multiplicador en los mercados financieros mundiales, en las tasas de interés y en la fluctuaciones y especulación en la bolsa de valores. Sin embargo, los organismos internacionales establecidos para garantizar la estabilidad financiera mundial no son capaces de enfrentarse a una de las distorsiones más fundamentales de la economía moderna.

Para América Latina, lener un vecino y su principal mercado en una recesión estruclural y con unos desbalances tan grandes como los senalados implica tener un factor desestabilizador permanente en sus propias economías. La Iniciativa para las Américas no puede analizarse fuera del contexlo de la necesidad de reajuste de la economía norteamericana y de la urgencia de aumentar su competitividad geoeconómica Irente a los megamercados de Europa y Japón.

Aquellos lalinoamericanos que consideran que la Iniciativa pudiera ser un faclor de crecimiento y estabilidad, como el molor de crecimiento que lue la economía norteamericana en los 60, cuando Estados Unidos era el país lider en inversión, tecnología y productividad, deben repensar la relación con Estados Unidos en un marco muy diferente.

Por otro lado, la monopolaridad militar de Estados Unidos, Irente a una multipolaridad económica donde Estados Unidos mantiene una posición de dibilidad crecienle no conduce a una situación de estabilidad. Como mantiene el profesor Paul Kennedy, los imperios en declive tienden a ser más beligerantes en términos militares para compensar su debilidad económica. 
Frente a la inicialiva para las Américas se pueden presentar Ires allernativas para América Latina:

1. Negociar mejores lérminos con la Iniciativa superando la falta de reciprocidad y la asimetría que el análisis del SELA presenla con claridad. Esta posición considera que la Inicialiva es la única tabla de salvación ante la crisis económica de América Latina.

2. Fortalecer los mecanismos de la integración subregional de América Latina integrándose el continente por subregiones (Merco Sur, Pacto Andino y Centroamérica Caribe con una relación especial con México, Colombia y Venezuela). Esta integración latinoamericana permitiría una complementariedad para enlrentar al mercado norleamericano y canadiense. Esla segunda allernativa pretende oblener los resullados más positivos de la iniciativa, diversificando la vinculación a Iravés de la integración de América Latina y abriéndose a nuevas relaciones con la Europa unida y con el Pacífico.

3. Hace surgir una visión y propuesta de sociedad latinoamericana alternativa. Se pretende aqui resolver las causas de la crisis económica y responder a las demandas acumuladas en la sociedad civil emergente. Se busca crear la base material para el mantenimiento y prolundización de una democracia participaliva. Se parte, por tanto, de una visión propia de sociedad, desde lo que se ha llamado la lógica de las mayorias, que busca cómo superar las tres explotaciones históricas del trabajo, de la naluraleza y de la soberanía. La crisis de civilización deshumaniza tanto a los vencedores como a los vencidos en el mercado y por tanto, exige recomponer equidad y simetria, incluso para que el mercado pueda ser genuinamente libre.

Esta alternaliva pretende reforzar las propuestas lalinoamericanas de la segunda alternativa. Esla visión y propuesta implica un mediano y largo plazo. Para los 90 lo más viable es avanzar y profundizar la integración y diversificación lalinoamericana en un marco de reciprocidad y simelria. Sin embargo, también un pragmatismo audaz exige tener una visión de la sociedad que vaya más allá de los marcos del mercado. La agenda latinoamericana no puede reducirse a la agenda de la Iniciativa para las Américas.

Esta alternativa implica algunas prioridades estratégicas:

1. Una estrategia de sobrevivencia y de tecnología apropiada en base a las experiencias acumuladas en la economía popular latinoamericana donde mal sobrevive la mayoría de la población.

2. Una fuerte inversión en capital humano, haciendo de los pobres agentes produclivos que superen su propia pobreza. En términos clá- 
sicos seria lo que Adam Smith llamaba la riqueza de la Nación.

3. El reconocimiento de la producción local y comercial como el espacio económico de las grandes mayorias latinoamericanas, que deben ser integradas al espacio del mercado interno y extendidas a proyectos subregionales para poder garantizar la autosuficiencia alimentaria y las exportaciones compelitivas de los sectores populares en el mercado inlernacional.

4. Una conexión selectiva con el mercado internacional y no una apertura absolula. Esto, hasta que se hayan logrado condiciones de mayor simetría y competilividad.

5. Politicas especiales para el sector inlormal, tanlo urbano como capesino que permitan crear un mercado interno con demanda efectiva capaz de incentivar la agroindustrialización y la manufactura. Sin la incorporación de los sectores más informales, la industria nacional será elitista y absolutamente dependiente de su contraparte transnacional. Esto exige la regionalización de esta propuesta en toda Lalinoamérica.

6. Ir haciendo cada vez más innecesario el Estado que es una entidad ambigua pero imprescindible en las etapas iniciales, al traspasar la sociedad civil y descentralizar el poder del Estado en las instituciones civiles. Usar el Estado como creador del marco social que fortalezca el crecimiento de las mismas organizaciones populares y de sus propias instituciones, a la vez que establece la capacidad negociadora a nivel regional e internacional.

7. La internacionalización del trabajo, de la tecnologia, de las insliluciones y del financiamiento de las organizaciones populares, exigida por la transnacionalización del capilal en el mercado mundial. Esto implica que las propuestas económicas alternativas busquen la internacionalización de estas experiencias para lograr la democratización del mercado nacional, latinoamericano y mundial.

La allernaliva popular parte del presupuesto de que un mercado monopólico produce un proceso de "darwinismo económico", asimétrico, donde el balance estatal desaparece, dado que el mercado sustiluye progresivamente al Estado y los más débiles son absorbidos por la concentración del capilal.

8. La democratización de las instiluciones internacionales, en especial el Fondo Monelario Inlernacional, el Banco Mundial y el BID, fundamental para establecer la equidad en las relaciones internacionales. Las instituciones internacionales funcionan actualmente como bandera de conveniencia del capital transnacional y del Grupo de los Siete. 
Son instituciones que nacieron en la Guerra Fria y mantienen ese clima, que responden a los intereses del Norte y que necesilan la democratización del poder dentro de las mismas.

La red internacional de las Organizaciones no Gubernamentales pudiera cumplir un papel importante en la democratización de estas insliluciones internacionales, abriendo un espacio a la representalividad del Sur en todas ellas.

El análisis de la experiencia de México y lambién de la del Canadá puede ser muy iluslraliva para el resto de América Latina.

Las primeras evaluaciones indican que la negociación rápida, no está permitiendo a México negociar en términos de equidad, reciprocidad y simelria. Además, el Tratado del Libre Comercio es fundamentalmente un tratado de libre inversión con plenas garantias supranacionales, es decir, no sometidas a los cambios jurídicos que polencialmente podría darse en México en un futuro. De esta forma se evitan los controles en Estados Unidos y los controles en México, al liempo que la abundante y barata manos de obra mexicana reduce la capacidad de negociación del sector Irabajo en Estados Unidos.

El pacto social que permitió la estabilidad política en México después de la Revolución se ha rolo con el último traude elecloral que llevó al poder a Salinas de Gortari y con las políticas del gobiemo de Salinas, que ha implicado que los salarios se hayan reducido de ser un $40 \%$ de PBI en 1976, a ser un $23 \%$ en 1990 . La sobreexplotación del trabajo, de la naturaleza y de la soberania en el marco de un llamado "mercado libre" puede ser lo que termine imponiéndose en todo el continente si no se consigue el balance que se propone en la segunda y lercera alternativa.

\section{La revoluclón de la socledad clvil}

Colón no sabia a dónde habia llegado al decubrir América. Este mal entendido fundacional persiste a los 500 anos. La llamada década perdida encubre, no permile descubrir, la realidad actual de América Latina.

La ingobernabilidad que caracteriza la crisis de los 90 implica la falta de una base material para la emergencia e imupción de la sociedad civil a Iravés de innumerables lormas organizativas de las masas y de la emergencia de nuevos sujelos históriccs. Intentaremos sinletizar algunos rasgos dominantes de esta nueva sociedad civil, cuya explosión ha quedado encubierta otra vez bajo la realida económica de la década perdida y bajo la cínica proclamación del fin de la historia. 
La mayorla de la sociedades latinoamericanas son en los 90 cualilativamente diferenles. Se han superado los viejos modelos oligárquicos, diclaloriales y militares. Un amplio proceso de desmilitarización se está dando incluso en las áreas de mayor conflicto bélico, como Centroamerica. En la mayoría de América Latina los militares están progresivamente sometiéndose al conirol civil. Los gobiernos autorilarios y las dicladuras militares se han abierto ante las presiones de la sociedad civil, dando paso a procesos electorales y a democracias, aunque éstas sean lodavia tuleladas y restringidas.

Sin embargo, el estacamiento, la dependencia y la inserción trasnacionalizada, sometida y asimétrica, son una herencia de los 80 . La cosecha de los 80 clarifica lambién la ambiguedad de la cooperación externa y del mercado internacional como molores de crecimiento y desarrollo.

En forma lelegráfica senalaremos algunos de los componentes de esta evolución de la sociedad civil. Incursionamos en un área de hipótesis y de sugerencias, algunas provocalivas, que llaman a la crealividad y a la honestidad política, porque si las propuestas no nos duelen en estos tiempos del cólera no habrá soluciones de a la crisis.

1. Crisis tiscal y desintegración del Estado. La deuda, el ajuste y la recesión económica generalizada han debilitado y en muchos paises desintegrado la capacidad reguladora del Estado (Perú, Argentina, Haiti, Dominicana, Panamá). El Estado en su función de propulsor se ha convertido en un factor de desregulación de la economia. La apertura indiscriminada y asimétrica al mercado internacional ha provocado lo que puede calificarse como inserción transnacionalizada, sometida y asimétrica.

2. Emergencia de nuevos movimientos populares. Producto de la pauperización creciente, de la polarización social y del desgaste de los partidos políticos tradicionales, tanto de la izquierda como de derecha han nacido y siguen naciendo. La lucha por la sobrevivencia ha provocado la reorganización, tanto en el sector informal como en el campesinado. Sin embargo, no encuentran cauces de acción con el Estado ni con los partidos politicos tradicionales, que no comprenden ni teórica ni práclicamente esla emergencia social.

EI movimiento de Lavalás en Haiti es posiblemenle el mejor símbolo de la capacidad de estas fuerzas populares de organizar una avalancha social que recrea a sus propios lideres, conlorma nuevas alianzas y grupos políticos y es capaz de derrocar una dictadura iniciando la reconstrucción de la nación y del propio Estado. 
3. La cristalización de una izquierda latinoamericana. En muchos sentidos esta izquierda responde a la hislórica visión que a fines del siglo XIX y comienzos del siglo XX tuvieron Martí, Mariátegui, Haya de la Torre, Sandino, Zapata, Recabarren y otros de nacionalizar la teoría. $Y$ corresponde a lo que por el mismo periodo en Europa lue sintetizado por Gramci. Indudablemente, esta nueva izquierda ha sidó alectada tanto por la crisis del socialismo del Este como por el estancamiento de la izquierda latinoamericana. Sin embargo, junto a la confusión y al desánimo inicial se ha provocado un luerte movimiento de creatividad y replanteamientos históricos, dando paso a lo que se ha llamado socialismo de las mayorias, socialismo criollo, socialismo del Tercer Mundo, buscando el socialismo de la sociedad civil. EI PT en Brasil y el cardenismo en México -no tanto el propio PRD- rellejan dinámicas similares. Lula, Aristide y Cárdenas simbolizan este tenómeno, que lienen manifestaciones peculiares en Colombia en el $\mathrm{M}$ 19 y en el Frente Amplio, de Uruguay. La profunda reestructuración polílica del FMLN y del FSLN en sus propios procesos revolucionarios parece indicar que existe conciencia de este fenómeno, que implica un replanteamiento de las funciones del partido en relación con la sociedad civil, el Estado y las fuerzas armadas.

En los innumerables encuentros que se han venido realizando entre estas nuevas fuerzas emergentes, existen algunas coincidencias fundamentales, que permiten pergenar el carácter de este nuevo liderazgo político frente al vacio dejado por los partidos tradicionales y neotradicionales, tanto de derecha como de izquierda, democracia cristiana, populista y foquista.

4. La radicalidad de la democracia como cultura, como método, como estilo y como proyeclo político. Por primera vez la izquierda ha tomado la democracia como bandera de lucha que caracleriza el resto de sus reinvindicaciones. La democracia participativa se prelende llevar a todos los niveles de la sociedad, respetando la independencia y autonomía de los movimientos y transformando el verticalismo e ideologismo que abundó en el pasado.

5. Un nuevo lenguaje político: "Prohibido prohibir" fue la consigna de Lula para el congreso del PT. "Un presidente en la oposición" fue la respuesla de Aristide al movimienlo campesino. Sólo son algunos indices de un lenguaje nuevo y de una pedagogia nueva que respeta los ritmos y la conciencia popular.

Existe un rechazo al lenguaje político de izquierda, lo mismo que al lenguaje oligárquico que Vargas Llosa utilizó en su campana. Collor de Mello, Fujimori y el propio Menem hicieron esfuerzos por adaptar 
el lenguaje, por crear un nuevo, pero tracasaron por no cambiar los contenidos.

Cabe hacer referencia aqui a la irrupción masiva del movimiento evangélico fundamentalista en América Latina. Las llamadas sectas implican la necesidad de revisar la misma teología de la liberación, de la pedagogía y práctica de las comunidades de base crislianas trente a eslas manifeslaciones de identidad y religiosidad popular que se han transformado en movimienlos escapistas y son base política para la derecha y ullraderecha. El avance del movimienlo evangélico fundamentalista expresa una seria debilidad e incluso un cierto fracaso de la teologia de la liberación. Es evidente el tinanciamiento proveniente de Estados Unidos y la infiltración política de la CIA en estos movimienlos evangélicos. Sin embargo, la religiosidad popular, en la que se manifiesta priorilariamente la cultura y conciencia de las masas empobrecidas, no fue adecuadamente captada ni trabajada por la teología de la liberación ni por las comunidades de base. El discurso teológico lue excesivamenle abstracto, teórico, politizado, sin dejar espacio suficiente a la celebración, a la alegria, al desahogo, a la participación espontánea de un pueblo agotado en la lucha por la sobrevivencia. Muchas veces lambién sobrecargado por demandas políticas que le exigian un espacio de expansión de su personalidad más intima.

6. Nuevas demandas, no sólo económicas, piden respuesta a un nuevo proyecto de sociedad, a nuevos valores, y a una nueva civilización. Eslas demandas provienen fundamentalmenle de los nuevos sujelos históricos - mujeres, indígenas, jóvenes y de la conciencia creciente sobre la crisis ecológica y la necesidad de recuperar la naturaleza para el hábitat popular.

'La temática, creatividad en el machismo político, abre enormes potenciales de rectificación, creatividad y de movilización popular. Las demandas de la mujer, de las etnias y los que claman por la conservación de la naturaleza son de las más radicales, alternalivas e internacionales. El paradigma tecnológico y neoliberal se encuentra desarmado ante estas demandas, que por otra parte han sido un reto no aceptado o siempre escamoleado por la izquierda tradicional.

7. Nueva concertación y nuevas alianzas. El cambio de la correlación de fuerzas internas en cada pais, debido a la prolongación y a la profundidad de la crisis, está llevando a acercamientos históricos inéditos entre amplios sectores de la sociedad a la vez que a la polarización de los grupos más exlremos e ideológicos. Eslo, que a primera vista pudiera parecer como una posición centrista, una tercera 
va, es ciertamente un movimiento ambiguo y fluctuante. Tiene componentes de agotamiento y confusión, a la vez que contiene aspiraciones y demandas no satisfechas por las pollticas, lanlo de la derecha como de la izquierda. No es una tercera vía que se niega a la derecha e izquierda, es la búsqueda de un consenso, de un denominador común que permita un proyecto nacional hegemonizado por las mayorias.

Los fenómenos de concertación económica que se están realizando en la mayoría de los países de América Latina se imponen sobre las ideologlas e incluso sobre los intereses de mediano plazo, buscando la estabilidad y la seguridad. Hegemonizar eslos grandes movimientos pluralistas de la sociedad civil es el arte de la política."La política es el arte de lo posiblen, aseveró uno de los pensadores más lúcidos de los tiempos modernos, y la política de los 90 necesila de este arte politico, que no claudique de los valores y principios sino que los profundice, los purifique y los adaple a las nuevas condiciones.

8. Los sectores no organizados. La vinculación con ellos es una de las tareas prioritarias y de las más dificiles para lograr hegemonizar el conglomerado y la dinámica de la sociedad civil.

La ampliación de la brecha cultural y política entre los grupos organizados y las crecienles masas desorganizadas exige nuevos estilos y nuevo liderazgo. El agotamiento del mensaje y de la imagen de los políticos en estos circulos mayoritarios es creciente. La ejemplaridad ética es una exigencia determinante en una cultura de las masas desorganizadas políticamenle. Es un lenguaje y un símbolo que mucho puede decir a una cullura amenazada por la desesperación y la falta de futuro.

9. La crisis de geslión y el problema de la eficiencia. En la era de la revolución técnica la eliciencia y la gestión son dos paradigmas del mundo actual. No ha sido ésta la característica más sobresaliente de los partidos y grupos con objelivos populares. La falia de credibilidad en la eficiencia de la izquierda, y por otra parte la milología de la eficiencia del sector privado, es olra de las tareas de esla década.

La crisis de gestión es también una crisis por el rilmo y la velocidad que imponen las nuevas tecnologias. Los cambios producidos por la sociedad de consumo han pueslo en comunicación directa la olerta con la demanda, al menos en la imaginación manipulada por las imágenes de los medios. Vincular la oferla real con la demanda real es una de las necesidades fundamentales de lo allernalivo. 
La crisis de gestión es también una crisis de medios de comunicación. Con razón Brzezinski afirmó que, además de la hegemonla militar, Estados Unidos hegemoniza los medios de comunicación, dado que de cada 5 imágenes o mensajes producidos en el mundo 4 están controlados por Estados Unidos. Los medios masivos y la pedagogía de la comunicación son fundamentales para la eficiencia de la gestión con las mayorias.

Por olro lado, la revolución del management implica desideologizar esta ciencia, considerada como burguesa, apropiándosela como un aporte a la socialización de los recursos disponibles. La vinculación eficiente y complementaria entre lo macro y lo micro es uno de los grandes aportes de la gestión lécnica y una necesidad económica, política e incluso militar.

10. La negociación y las alianzas como fuerzas políticas. La superación del confliclo Esle y Oeste y una nueva cullura de paz y lolerancia, después de décadas de alianzas ideológicas polarizantes, hacen de la negociación y de la alianza instrumentos privilegiados, tanto para la caplación del enemigo, como para lograr la hegemonía sobre el pluralismo y la diversidad de la sociedad civil. La alianza ideológica que bipolarizó el mundo ha dejado un vacio de vínculos y valores para la creación del Nuevo Orden Mundial. Un mundo global requiere de una alianza de valores comunes capaces de articular la civilización global del siglo XXI, una alianza de intereses materiales comunes que permilan unos objelivos de gran consenso mundial, una alianza frente a amenazas comunes (crisis ecológicas, seguridad común y desarme, crisis regionales, elc.). Sin esla alianza, el poder político impueslo delerminará el futuro dentro de los parámelros que nos han conducido a la actual crisis de civilización.

\section{Agenda popular para los 90}

Década compleja, década que se inicia con la derrola sandinista, con la creciente desintegración del socialismo de Europa del Esle, con la división del Sur aumentada tras la crisis del Golfo, con la actual incongruencia del Movimiento de los No Alineados...La Pax Americana implica una derrola para los "condenados de la lierra" y la formación de un nuevo trilaterismo coordinado por el Grupo de los Siete, que en medio de sus contradicciones suponen un poder de hecho que impide los cambios que el Sur necesita.

Eslados Unidos ha superado el síndrome de Vietnam con la vicloria del Gollo y consolida la fuerte coalición de los círculos de poder económico, político e ideológico norteamericanos. La alianza de los tres gran- 
des lobbys norteamiericanos, - el pelroleo, el armamentista y el judioen tomo a la crisis del Golfo supera en fortaleza la alianza que llevó el proyecto de la nueva derecha y a Reagan al poder, al CPD (Comitlee of the Present Danger). Las raices ideológicas de la Doctrina Truman de los anos 40 y la política exterior del Consejo Nacional de Seguridad formulada en 1950 y conocida en Estados Unidos como NSC 68, se ha fortalecido con la victoria en el Golfo. Incluso se pretende establecer una alianza especial entre Estados Unidos y Japón que Brzezinski llamó Ameripón.

Por otro lado, los contrapesos internacionales están desapareciendo, en primer lugar en el Este, en segundo lugar en la NOAL, y en tercero, en los organismos internacionales, especialmente las Naciones Unidas, que ha quedado paralizada ante el poder de veto de las cinco grandes potencias de la Guerra Fria.

Desde la perspectiva de los paises del Sur esla avalancha es una amenaza comparable a lo que lue la del fascismo en Europa. Enfrentarla requiere de una alianza amplia en cada pais y entre los paises, incluyendo a los nuevos sujelos históricos del Norte, minoritarios pero cada vez más conscientes de que esta crisis de civilización es lanto del Norte como del Sur.

Hace falta repensar una leoria global del socialismo o de las atternativas no capitalistas.

El viejo debate del socialismo en un sólo pais vuelve a demostrar hoy la imposibilidad de su sobrevivencia, realidad que ya Lenin visualizo a comienzos del siglo si el socialismo no se extendia por Europa. La falta de un proyecto global de cambio y de acumulación de fuerzas hará imposible o extraordinariamente cosloso el proyecto alternativo en un solo país.

La triangulación del Trabajo y del Sur. Eslos dos sujetos sociales internacionales se están convocando en diversas formas, en todas las partes del mundo, a través de foros políticos, sindicales, religiosos, de ONG y por primera vez han comenzado a vincularse internacionalmente. Ejemplos son el proyecto japonés asiático People'sPlan 21 (PP21), que aglutina a cientos de organizaciones de Japón y del Pacífico; el Third World Networkyel Forum for People's Economic, que articulan a numerosos gnupos de invesligadores del Norte y del Sur y eslán Irabajando en alternativas económicas al proyecto neoliberal.

La red de ONG europeas y del Sur, los partidos politicos que se han organizado en tomo al proyecto socialismo del futuro, que incluye por primera vez a las diversas tendencias de la izquierda europea -comu- 
nistas, trotskistas, socialistas - la casa común del sociallsmo, se orlgino en un encuentro entre Gorbachov, Willi Brandt y Emest Mandel promovido por el lilósofo polaco Adam Schalt. Intentan poner entre paréntesis las diferencias históricas de la izquierda para crear lo que llaman el humanismo ecuménico. Aunque este proyecto de grandes hombre no ha producido más que pocas y pequenas ideas en relackón con el Sur, lo significlativo de estos ejemplos es la creciente tendencia a esta Iransnacionalización de las allernativas no capitalistas que tienen a las mayorlas como su lógica dominante.

Sin embargo, en un mundo global, no hay ya revoluciones antis sino proyectos y propuestas pro. El anliimperialismo y el nocapitalismo han de ser repensados dentro de los grandes cambios globales y dentro de una cultura de paz y de democracia, donde cualquier forma de imperialismo pierda legitimidad y quede aislado al ser percibido como "el enemigo de la humanidad". Eslo requiere de una contextualización que pueda incluir a amplios seclores del Norte y sobre todo del pueblo norteamericano, en torno a una agenda internacional para los 90 que presente propuestas comunes y viables. Esto exige iniciar el proceso de las agendas populares pais por pais en América Latina para ir enconirando las sintesis acumulalivas y de consenso inlernacional en lodos los toros $\theta$ instituciones donde se plantee la problemática del Nuevo Orden.

En la reunión de parlidos políticos en Viena se propuso que la Conferencia Mundial de las Naciones Unidas Je julio/92 en Brasil y la de la UNCTAD en Colombia (febrero/82), fuesen las platalormas iniciales del lanzamiento de propuestas allemativas globales, desde numerosos países e innumerables organizaciones populares de lodos los conlinentes.

Se requiere de una aclilud creativa y ofensiva, superando la propuesta sin propuesta para presentar las propuestas con prolesla que necesitan lazarse ya.

Pensar y analizar alternativamente en estos tiempos del collera produce anguslia. Y no se puede pensar sin dolor. Pero mientras el pensamiento no angustie y duela habrá crisis de ideas y sobre lodo de altemativas. Le estaríamos dando si no la razón a Fukuyama que afirma que la política puede seguir pero la historia ideológica ha terminado.

Esta utopía en plena crisis ante el tolalitarismo tecnológico, que no deja margen a un fuluro o a una esperariza que no se someta a sus parámetros. La crisis de civilización no es un conceplo sino una realidad que necesila de una nueva sínlesis histórica. Puede parecer romántico el considerar que en 1992, a 500 años del inicio de la Historia Universal y que en América Latina, continente mestizo, de sintesis raciales, cultu- 
rales e históricas se pueda olrecer la oportunidad de iniciar esle proceso. Entre la esperanza y el desastre; asi puede calificarse la dialéclica de sentimientos encontrados que nos envuelve en esla coyuntura. Pablo Neruda, en otra coyuntura también hislórica, plasmó magistralmente esle mismo sentimiento al decir: "Podrán cortar lodas las flores, pero no podrán detener la primavera". 